Jurnal ELTIKOM, Vol. 1 No.2, Desember 2017, Hal 64-70

ISSN 2598-3245 (Print), ISSN 2598-3288 (Online)

Tersedia Online di http://eltikom.poliban.ac.id

\title{
PREDIKSI HARGA EMAS MENGGUNAKAN METODE NEURAL NETWORK BACKROPAGATION ALGORITMA CONJUGATE GRADIENT
}

\author{
Yuslena Sari \\ Program Studi Teknologi Informasi Unvesitas Lambung Mangkurat \\ e-mail: yuzlena@unlam.ac.id
}

\begin{abstract}
Artificial Neural Network Backpropagation is known as one of the most reliable methods of predicting. The algorithm used in this research is Conjugate Gradient algorithm, with gold data data of input data for training data. The price of gold becomes an issue in the market, as a precious metal that can be used for investment is very interesting to make a gold price prediction application. Gold prices continue to increase in the world market, making investors interested to invest in this precious metal. The application of gold price prediction will be very useful for investors of precious metals. Gold price data used in this research is daily data, taken 3 (three) last year and divided into test data and data testing. Test data is used to generate new weights for data testing. The parameters used in the measurement of evaluation of predicted results from Conjugate Gradient algorithm Artificial Neural Network Backpropagation method is Meant Square Error (MSE), where the result of MSE from this research is 0.0313651
\end{abstract}

Kata Kunci: Conjugate Gradient, Artificial Neural Network, Backpropagation, Prediction, Gold

\begin{abstract}
ABSTRAK
Artificial Neural Network Backpropagation dikenal sebagai salah satu metode yang handal dalam memprediksi. Algoritma yang digunakan pada penelitian ini adalah algoritma Conjugate Gradient, dengan data harga emas data inputan untuk data latih. Harga emas menjadi isu tersendiri di pasaran, sebagai logam mulia yang dapat digunakan untuk investasi sangat menarik untuk dibuat sebuah aplikasi prediksi harga emas. Harga emas terus meningkat di pasaran dunia sehingga membuat para investor banyak tertarik untuk berinvestasi pada logam mulia ini. Aplikasi prediksi harga emas akan sangat berguna untuk investor logam muliai. Data harga emas yang digunakan dalam penelitian ini adalah data harian, diambil 3 (tiga) tahun terakhir dan dibagi menjadi data uji dan data testing. Data uji digunakan untuk menghasilkan bobot baru untuk data testing. Parameter yang digunakan dalam pengukuran evaluasi hasil prediksi dari algoritma Conjugate Gradient metode Artificial Neural Network Backpropagation adalah Meant Square Error (MSE), dimana hasil MSE dari penelitian ini adalah 0.0313651
\end{abstract}

Kata Kunci: Conjugate Gradient, Artificial Neural Network, Backpropagation, Prediksi, Emas

\section{PENDAhUluan}

$\mathrm{E}$ mas telah menjadi salah satu pemain top di kelas aset tahun ini naik menjadi $11 \%$. Banyak perusahaan tidak percaya tentang kenaikan baru-baru ini akan berberkelanjutan. Tiga faktor aktivitas ekonomi AS yaitu cuaca-dampak, kekhawatiran kredit Cina dan Ukraina ketegangantelah memainkan peran dalam mendorong harga emas lebih tinggi pada tahun 2014. Emas merupakan sebuah aset yang memiliki nilai tinggi dan akan naik setiap saat, berbeda dengan saham, yang nilainya naik turun sesuai dengan keadaan pasar, di sinilah pentingnya seseorang memiliki simpanan emas. Namun kebanyakan orang lebih memilih untuk berinvestasi dengan cara lain, tanpa tau kentungan dalam berinvestasi emas[1].

Makalah ini menggunakan Artificial Neural Network Backpropagation untuk memprediksi harga emas yang sangat popular di decade terakhir ini. Algoritma Conjugate Gradient diterapkan pada aplikasi prediksi ini untuk mengoptmasi bobot dalam pelatihan. Sistem yang dikembangkan berdasarkan time series dengan data harian dari harga emas. Sebelum Artificial Neural Network ada beberapa metode 
metode klasik yang banyak diterapkan dibanyak aplikasi. Metode linier diantaranya adalah Auto Regressive Moving Average (ARIMA) dan Multiple Regression. Artificial Neural Network adalah metode nonlinier yang banyak digunakan dalam berbagai variasi bidang industri, bisnis dan ilmu pengetahuan dan yang paling banyak digunakan adalah untuk prediksi secara time series. Karakteristik Artifial Neural network merupakan metode berstruktur nonlinier, fleksibel dan berbasis pembelajaran dengan kemampuan memproses data dengan perkiraan fungsi universal. Hal ini yang membuat Artificial Neural Network sesuai diaplikasikan untuk prediksi. Backpropagation merupakan metode dalam Artificial Neural Network yang memiliki tingkat akurasi yang tinggi dalam penerapan pada prediksi. Metode berbasis gradien adalah salah satu yang paling banyak digunakan pada metode backpropagation untuk minimisasi error dengan cara melatih kembali jaringan propagasi. Algoritma pelatihan Backpropagation adalah sebuah metode pembelajaran yang diawasi untuk multi-layered feed-forward neural network. Pada dasarnya gradien ini adalah teknik optimasi lokal yang melibatkan koreksi kesalahan dari bobot jaringan. Terlepas dari keberhasilan umum Backpropagation dalam mempelajari neural networkjaringan, beberapa kekurangan utama masih perlu dipecahkan. Pertama, algoritma Backpropagation akan terjebak di local minima terutama untuk permasalahan non linier. Setelah terjebak dalam minima lokal, Backpropagation mungkin menyebabkan kegagalan dalam menemukan pemecahan masalah yang optimal. Kedua, tingkat konvergensi Backpropagation masih terlalu lambat saat pembelajaran. Selanjutnya, perilaku konvergensi algoritma BP sangat tergantung pada pilihan nilai awal bobot dan parameter dalam algoritma seperti tingkat belajar dan momentum. [2][3][4].

Namun, telah ditemukan variasi dalam memodifikasi gradien lokal untuk memberikan gradasi yang lebih baik untuk setiap iterasi pembelajaran. Fakta ini memungkinkan kita untuk mengembangkan dan menyelidiki beberapa formula Conjugate Gradient untuk meningkatkan tingkat konvergensi jenis algoritma yang diusulkan[5]. Studi ini menunjukkan bahwa modifikasi sederhana arah pencarian juga dapat memperbaiki secara substansial efisiensi pembelajaran dengan metode optimasi.

\section{LANDASAN TEORI}

\section{A. Backpropagation}

Neural network atau jaringan syaraf tiruan adalah metode yang penting digunakan pada data mining terutama untuk prediksi. Artificial Neural Network bisa dikatakan usaha untuk membangun mesin yang meniru aktivitas otak dan bisa belajar. Artificial Neural Network biasanya belajar dengan contoh. Jika Artificial Neural Network diberkan contoh yang cukup, seharusnya bisa untuk melakukan prediksi dan bahkan menemukan tren atau pola baru dalam data. Dasar Artificial Neural Network terdiri dari tiga layer, input, output dan hidden layer. Setiap lapisan bisa memiliki nomor dari node dan node dari layer input terhubung ke node dari hidden layer. Node dari hidden layer terhubung ke node dari layer output. Koneksi tersebut mewakili bobot antar node[6]. Salah satu algoritma Artificial Neural Network yang paling populer, yaitu algoritma Backpropagation. Tujuannya adalah untuk menunjukkan logika dibalik algoritma ini. Ide dibalik algoritma Backpropagation cukup sederhana, output dari neural network dievaluasi terhadap output yang diinginkan. Jika hasilnya tidak memuaskan, koneksi (bobot) antar lapisan dimodifikasi dan proses diulang lagi dan lagi sampai error cukup kecil[6][7][8]. Contoh arsitektur Backpropagation Artificial Neural Network sederhana ditunjukkan pada gambar 1.

Salah satu sifat neural network yang ada pada Backpropagation adalah memiliki arsitektur multilayer network. Multilayer adalah jaringan dengan lapisan yang banyak dan memiliki 3 jenis layer yaitu input layer, hidden layer dan output layer. Hidden ini bersifat variable, dapat digunakan lebih dari satu hidden layer.[3][2][9]

\section{B. Algoritma Conjugate Gradient}

Algoritma Conjugate Gradient adalah metode pencarian lain yang dapat digunakan untuk meminimalkan keluaran jaringan kesalahan dalam arah konjugasi pada Backpropagation. Salah satu sifat yang luar biasa dari metode Conjugate Gradient ini adalah kemampuan untuk menghasilkan satu set vektor dengan properti yang dikenal sebagai konjugasi dengan cara yang sangat ekonomis. Cara metode Cojugate Gradient meminimalkan fungsi diferensial bobot baru dengan rumus: 


$$
w_{k+1}=w_{k} \alpha_{k} d_{k}
$$

$$
\text { Input Layer Hidden Layer Layer } \quad \text { Output Layer }
$$

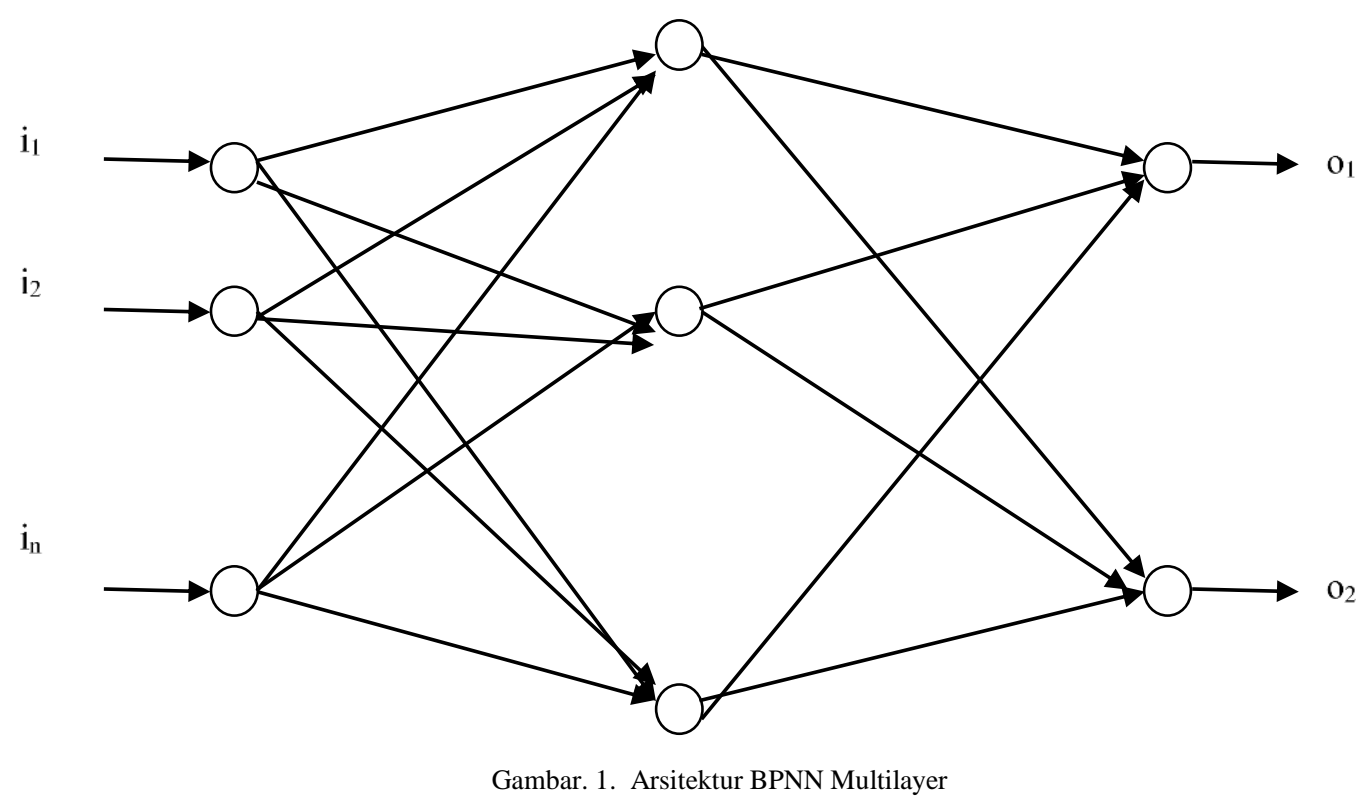

Arah kojungsi dengan perubahan bobot yang telah dilakukan untuk meminimalkan fungsi kinerja dalam pelatihan jaringan. Bobot tersebut dsetting sesuai dengan arah konjungsi. Pendekatan pada optimasi bobot menggunakan fungsi line search dalam pencarian arah konjungsi guna meminimalisasi nilai mean square error(MSE) selama arah pencarian. Adapun rumus line search:

$\beta=\frac{{ }_{t+1}{ }^{T}\left[g_{t+1-} g_{t}\right]}{g_{1} T_{g_{t}}}$

\section{Parameter Evaluasi Prediksi}

Untuk mengevaluasi akurasi dan peramalan kinerja model berbeda, ada beberapa parameter evaluasi untuk prediksi diantaranya Mean Square Error (MSE), Root Mean Square Error (RMSE) dan Mean Absolute Deviation (MAD), Percentage Error (MAPE) [10][11][12]. Fungsi perhitungan parameter evaluasi tersebut:

\section{a. Mean Square Error (MSE)}

Mean Square Error kebanyakan digunakan untuk prediksi, dengan rumus:

$M S E=\frac{\sum(\text { Aktual }- \text { Prediksi })^{2}}{n}$

\section{b. Root Mean Square Error (RMSE)}

Root Mean Square Error adalah aturan penilaian kuadrat yang juga mengukur besarnya rata-rata kesalahan. Ini adalah akar kuadrat rata-rata perbedaan kuadrat antara prediksi dan pengamatan aktual.

$R M S E=\sqrt{\frac{\sum(\text { Aktual-Prediksi })^{2}}{n}}$

\section{c. Mean Absolute Deviation (MAD)}

Mean Absolute Deviation mengambil nilai absolut dari perkiraan kesalahan dan rata-rata kesalahan sepanjang periode perkiraan waktu. Mengambil nilai absolut dari sebuah nomor mengabaikan apakah jumlahnya negatif atau positif dan, dalam kasus ini, menghindari hal positif dan negatif yang saling membatalkan, dapat dirumuskan: 
$M A D=\frac{\sum \mid \text { Aktual }- \text { Prediksi } \mid}{n}$

\section{d. Mean Absolute Persentage Error (MAPE)}

Mean Absolute Percentage Error adalah ukuran kesalahan perkiraan yang paling umum. Fungsi MAPE paling baik bila tidak ada angka ekstrem pada data (termasuk angka nol). Dengan angka nol atau mendekati nol, MAPE dapat memberi gambaran kesalahan yang menyimpang. Kesalahan pada item mendekati nol bisa sangat tinggi, menyebabkan distorsi pada tingkat kesalahan keseluruhan saat dirataratakan. Rumusnya pada persamaan 6:

$M A P E=\frac{\sum \frac{\mid \text { Aktual-Prediksi } \mid}{\text { Aktual }} \times 100}{n}$

Pada penelitian ini menggunakan parameter evaluasi MSE.

\section{METODE PENELITIAN}

\section{A. Metode Pengumpulan Data}

Data yang dikumpulkan pada studi ini terbagi menjadi 2 (dua) jenis data yaitu:

a. Data Primer

Adalah data studi untuk dijadikan sebagai data pembelajaran dan pelatuhan, data didapat dari website harga emas sebanyak 3 (tiga) tahun yaitu mulai tahun 2014 sampai tahun 2016.

\section{b. Data Sekunder}

Data sekunder adalah data - data yang didapat secara tidak langsung yaitu dari jurnal, buku dan makalah yang digunakan pada studi ini.

\section{B. Metode Pengolahan Awal Data}

Pengolahan data harga emas dimulai dari pengumpulan data harian selama 3 (tiga tahun) yaitu tahun 2014 -2016 kemudian data dibagi menjadi dua. Data tersebut adalah data pelatihan dan data uji. Data pelatihan diambil data tahun 2014 dan 2015 sedangkan data untuk uji adalah data tahun 2016. Data harga emas menjadi inputan pada jaringan dan data akan dilatih untuk satu langkah ke depan sampai $n$ inputan dan satu data paling depan sebagai target. Adapun ilustrasi data inputan dan target untuk prediksi harga emas ini ditunjukkan gambar 2.
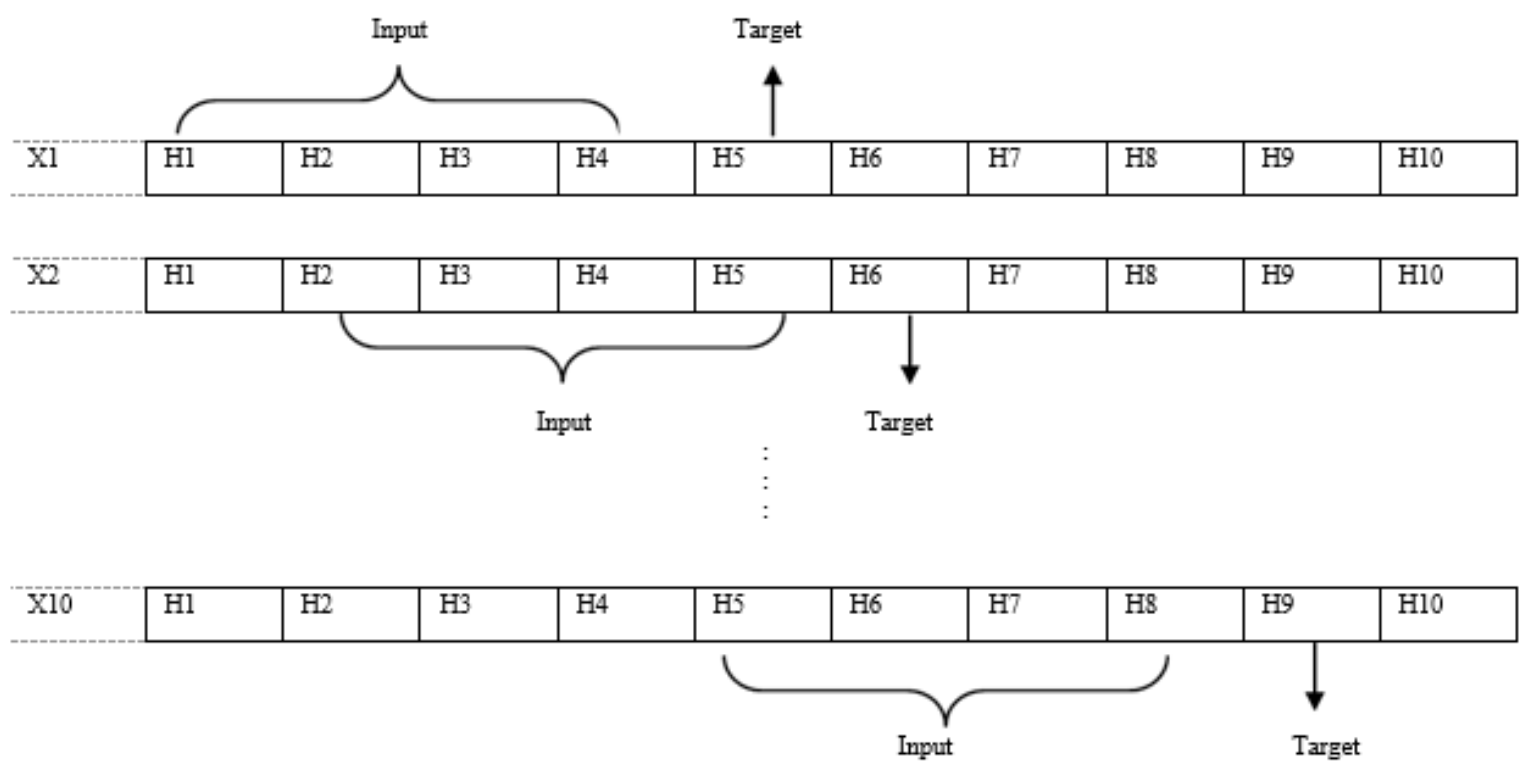

Gambar. 2. Ilustrasi prediksi data inputan ke dalam jaringan 


\section{Metode Yang Diusulkan}

Metode yang digunakan untuk pelatihan ini adalah Backpropagation Artificial Neural Network dengan optimasi palatihan Conjugate Gradient learning dan di implementasikan dengan Matlab.

\section{Hasil Perancangan Dan Pembahasan}

\section{A. Hasil Perancangan Aplikasi}

Pembagian data ada dua, yaitu training data dan testing data, training data terbagi dari data input dan target. Training data dan input data diruntun dalam excel. Epoch diset 100, goal $=0.1$ dan learning rate $=0.01$. Output yang dihasilkan adalah hasil prediksi dan mean square error.

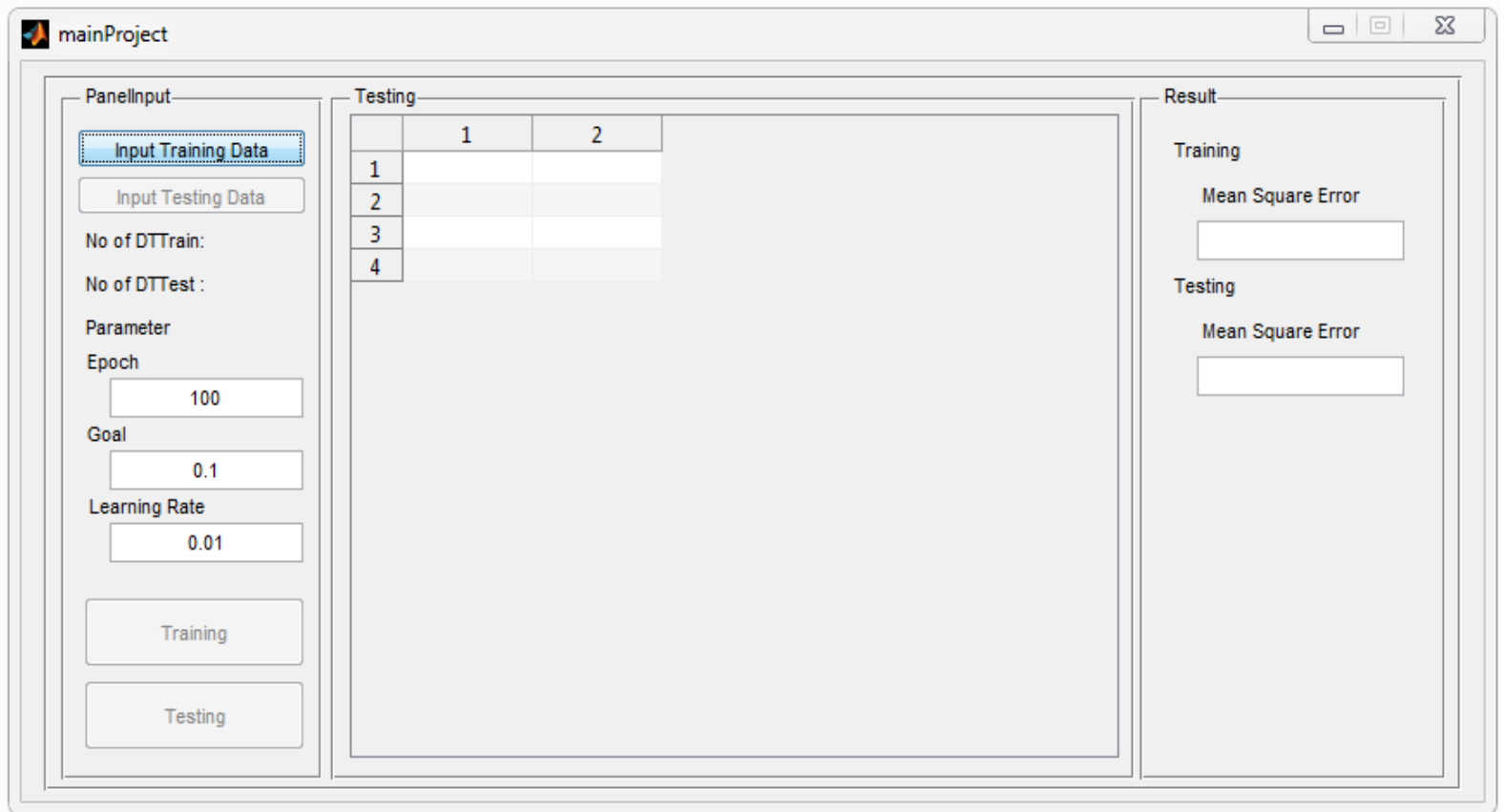

Gambar. 3. Aplikasi prediksi harga emas

Terlebih dahulu adalah data training untuk menghasilkan bobot yang terbaik untuk dipakai pada data uji.

\begin{tabular}{|c|c|c|c|c|c|c|c|}
\hline \multicolumn{7}{|c|}{$\Gamma^{\text {Panellnput_- }}-$ Training- } & \multirow{4}{*}{$\begin{array}{l}\text { - Result- } \\
\text { Training } \\
\text { Mean Square Error }\end{array}$} \\
\hline \multirow{2}{*}{ Input Training Data } & xt & xt-1 & $x t-2$ & $x t-3$ & $x t+49$ & \multirow[b]{2}{*}{ 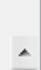 } & \\
\hline & $1.0909 e+04$ & $1.0817 e+04$ & $1.0769 e+04$ & $1.0702 e+04$ & $1.0796 \mathrm{e}+04$ & & \\
\hline Input Testing Data & $1.0817 e+04$ & $1.0769 e+04$ & $1.0702 e+04$ & $1.0823 e+04$ & $1.0829 e+04$ & & \\
\hline No of DTTrain: $\quad 687$ & $1.0769 e+04$ & $1.0702 e+04$ & $1.0823 e+04$ & $1.0819 e+04$ & $1.0835 e+04$ & & \multirow{4}{*}{$\begin{array}{l}\text { Testing } \\
\text { Mean Square Error }\end{array}$} \\
\hline \multirow{2}{*}{ No of DTTest: } & $1.0702 e+04$ & $1.0823 e+04$ & $1.0819 \mathrm{e}+04$ & $1.0822 e+04$ & $1.0875 e+04$ & & \\
\hline & $1.0823 e+04$ & $1.0819 e+04$ & $1.0822 e+04$ & $1.0814 e+04$ & $1.0818 \mathrm{e}+04$ & & \\
\hline Parameter & $1.0819 e+04$ & $1.0822 e+04$ & $1.0814 \mathrm{e}+04$ & $1.0817 e+04$ & $1.0728 \mathrm{e}+04$ & & \\
\hline Epoch & $1.0822 e+04$ & $1.0814 \mathrm{e}+04$ & $1.0817 e+04$ & $1.0843 e+04$ & $1.0769 e+04$ & & \\
\hline 150 & $1.0814 e+04$ & $1.0817 e+04$ & $1.0843 e+04$ & $1.0775 e+04$ & $1.0763 e+04$ & & \\
\hline Goal & $1.0817 e+04$ & $1.0843 e+04$ & $1.0775 e+04$ & $1.0785 e+04$ & $1.0782 e+04$ & & \\
\hline 0.01 & $1.0843 e+04$ & $1.0775 e+04$ & $1.0785 e+04$ & $1.0763 e+04$ & $1.0750 \mathrm{e}+04$ & & \\
\hline Learning Rate & $1.0775 e+04$ & $1.0785 e+04$ & $1.0763 e+04$ & $1.0742 e+04$ & $1.0804 \mathrm{e}+04$ & & \\
\hline \multirow{3}{*}{0.001} & $1.0785 e+04$ & $1.0763 e+04$ & $1.0742 e+04$ & $1.0717 e+04$ & $1.0911 e+04$ & & \\
\hline & $1.0763 e+04$ & $1.0742 e+04$ & $1.0717 e+04$ & $1.0769 e+04$ & $1.0861 e+04$ & & \\
\hline & $1.0742 e+04$ & $1.0717 e+04$ & $1.0769 e+04$ & $1.0803 e+04$ & $1.0847 e+04$ & & \\
\hline \multirow{2}{*}{ Training } & $1.0717 e+04$ & $1.0769 \mathrm{e}+04$ & $1.0803 e+04$ & $1.0794 e+04$ & $1.0778 \mathrm{e}+04$ & & \\
\hline & $1.0769 e+04$ & $1.0803 e+04$ & $1.0794 e+04$ & $1.0721 e+04$ & $1.0806 \mathrm{e}+04$ & & \\
\hline \multirow{3}{*}{ Testing } & $1.0803 e+04$ & $1.0794 e+04$ & $1.0721 \mathrm{e}+04$ & $1.0674 e+04$ & $1.0777 \mathrm{e}+04$ & \multirow[b]{3}{*}{+} & \\
\hline & $1.0794 \mathrm{e}+04$ & $1.0721 e+04$ & $1.0674 \mathrm{e}+04$ & $1.0672 e+04$ & $1.0692 e+04$ & & \\
\hline & \begin{tabular}{|l|l|}
10 & $107210+010$ \\
\end{tabular} & 1 natdanom & 1 กละ72a+na & 1 nesposna & $108800+010$ & & \\
\hline
\end{tabular}

Gambar. 4. Data training

Setelah data training di inputkan maka akan dilakukan training atau pembelajaran untuk mendapatkan bobot yang akan digunakan pada data testing. 


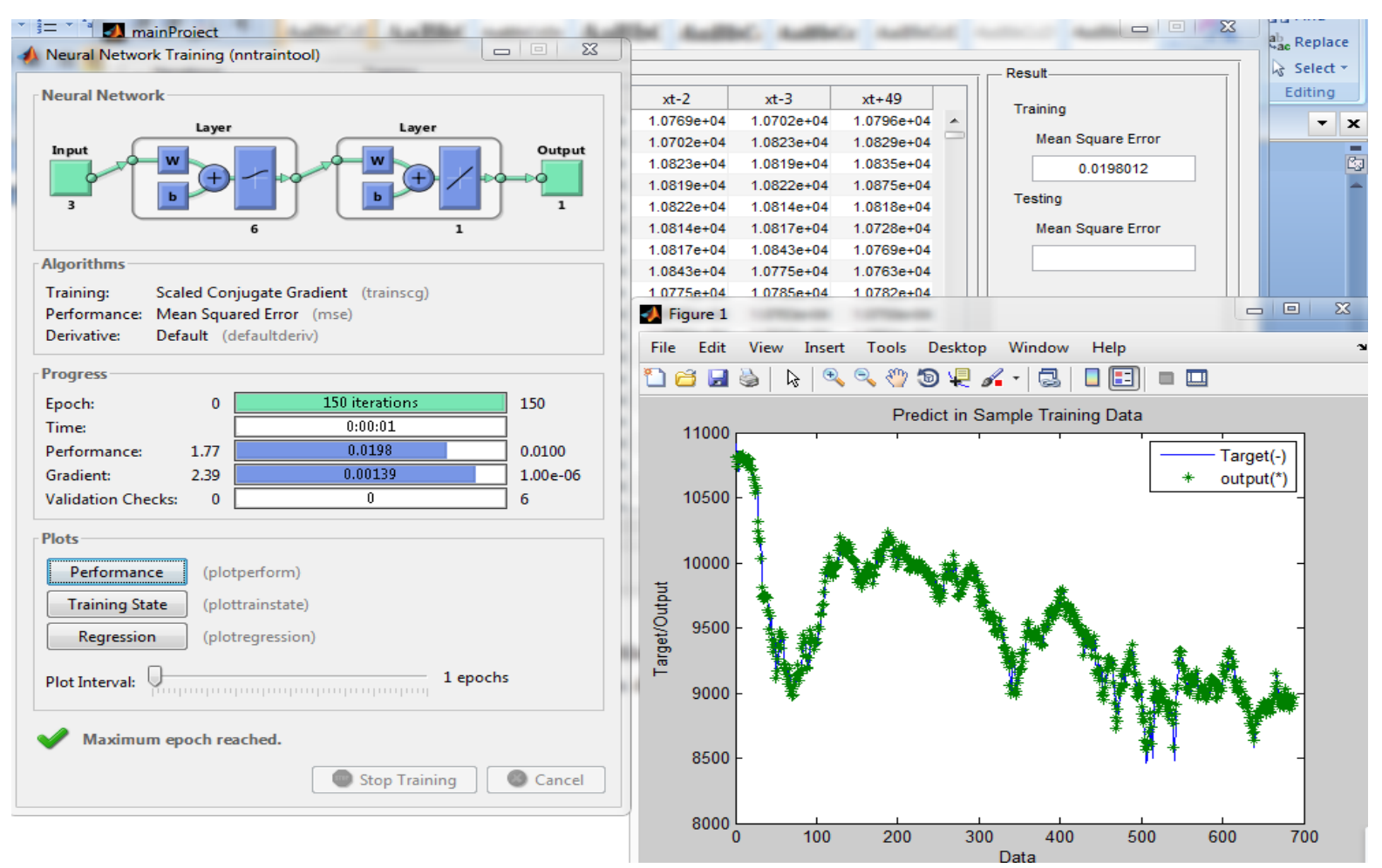

Gambar. 5. Hasil data training

Dari hasil pembelajaran maka di dapat nilai $\mathrm{MSE}=0.0198$, dan bobot yang baru disimpan untuk digunakan pada testing data. Setelah hasil training didapatkan maka aplikasi akan meminta data inputan untuk uji atau testing.

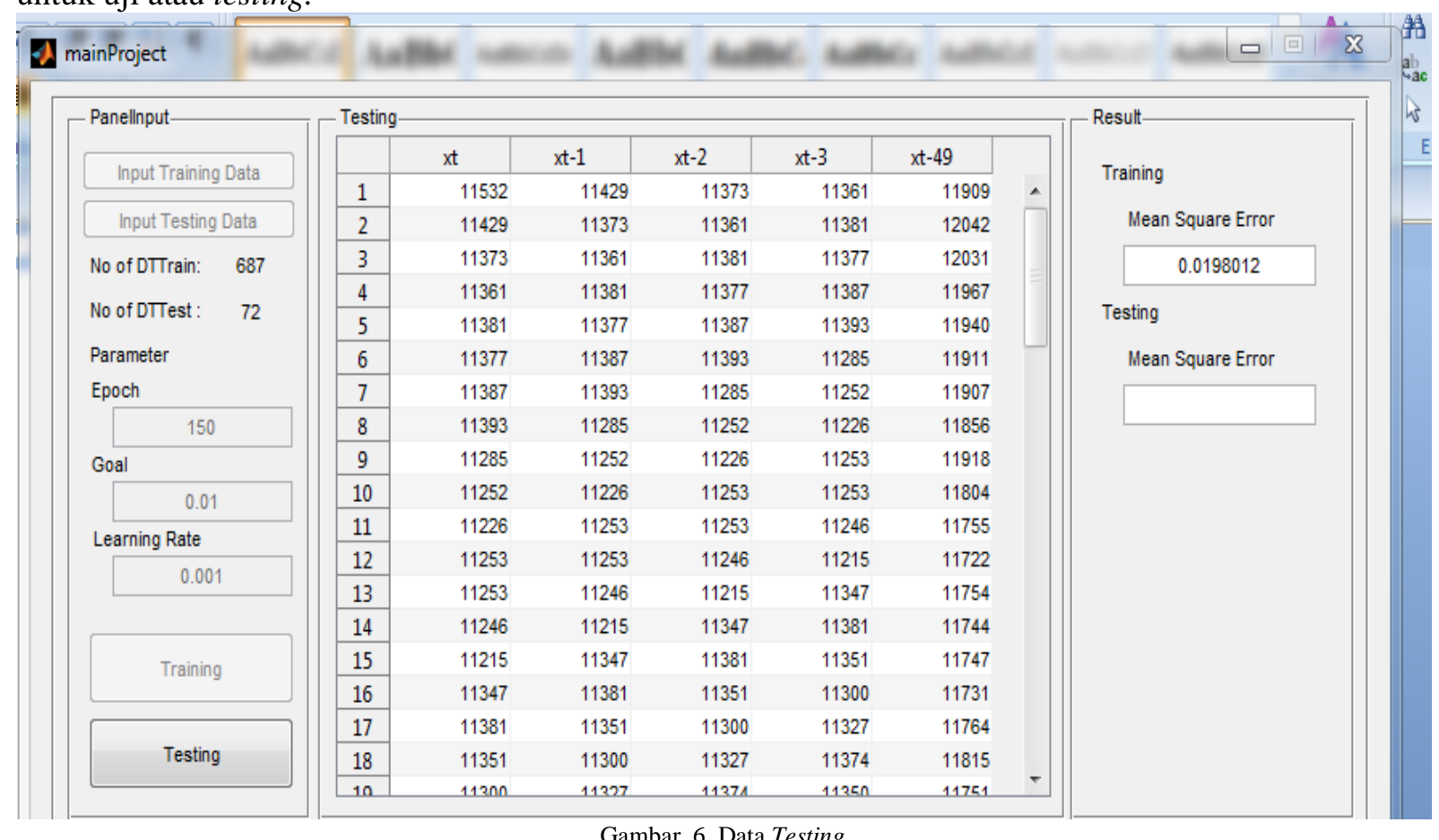

Setelah data testing di input, maka didapat hasil: 


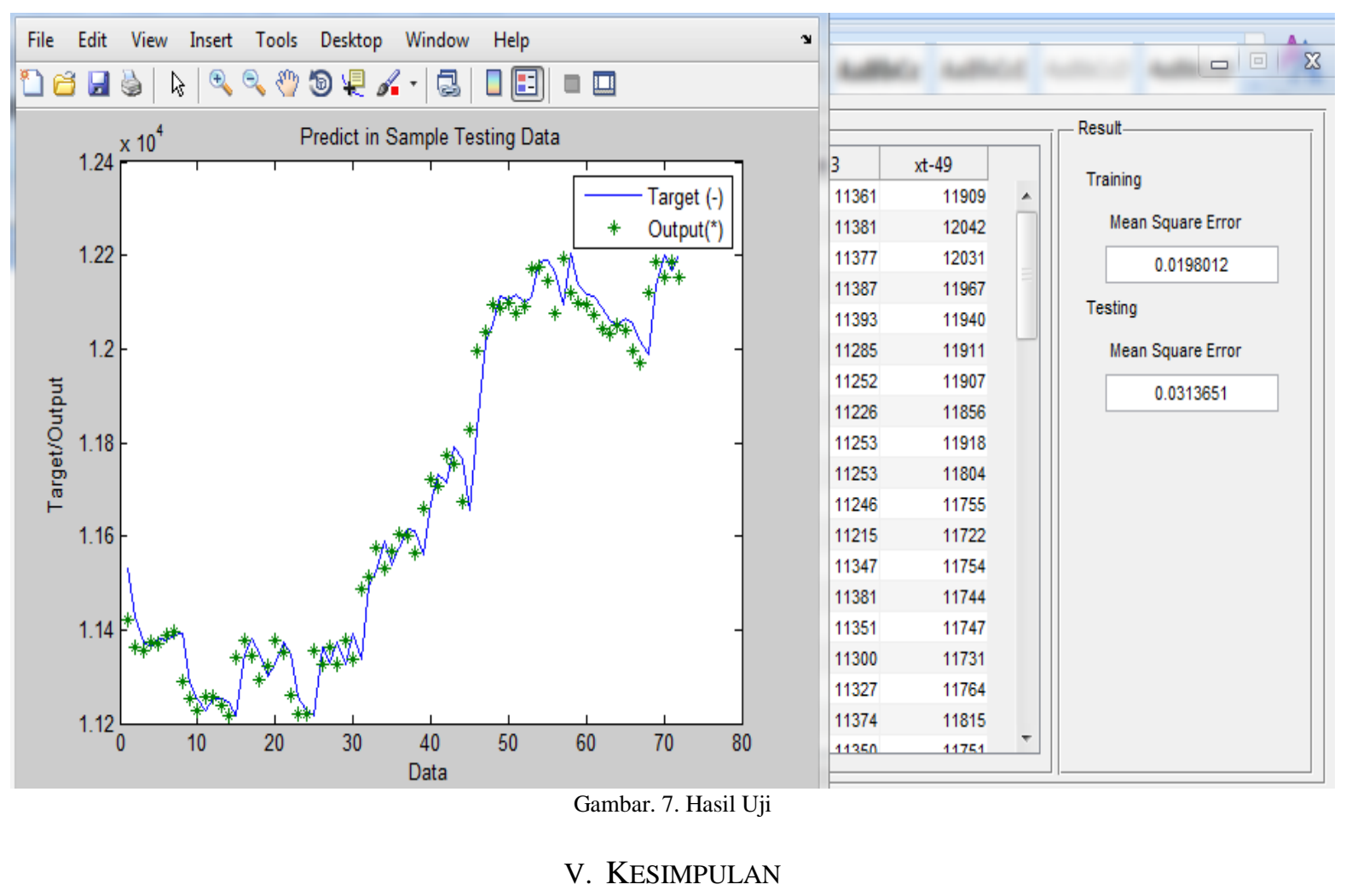

Penerapan algoritma Conjugate Gradient Artificial Neural Network Backpropagaion dapa memprediksi dengan baik, menghasilkan nilali MSE $=0.0313651$ untuk data testing dan $\mathrm{MSE}=0.0198012$ untuk data uji dengan setingan 100 epoch, goal $=0.1$ dan learning rate $=0.01$. Untuk menghasilkan prediksi yang lebih baik dapat ditambahkan data inputan yang lebih banyak agar pola pembelajaran pada data uji dapat menghasilkan MSE yang lebih kecil.

\section{DAFTAR PUSTAKA}

[1] J. H. Yang and W. Dou, “A new prediction method of gold price: EMD-PSO-SVM,” J. Softw., vol. 9, no. 1, pp. 195-202, 2014.

[2] M. Kangaranifarahani and S. Mehralian, "Comparison Between Artificial Neural Network and Neuro-Fuzzy for Gold Price Prediction," 2013.

[3] S. Faisal et al., "Gold Price Prediction Using Radial Basis Function Neural Network," 2011.

[4] Y. Sari and R. A. Pramunendar, "Classification Quality of Tobacco Leaves as Cigarette Raw Material Based on Artificial Neural Networks," Int. J. Comput. Trends Technol., vol. 50, no. 3, pp. 147-150, 2017.

[5] A. Y. Al Bayati, N. A. Sulaiman, and G. W. Sadiq, "A Modified Conjugate Gradient Formula for Back Propagation Neural Network Algorithm," vol. 5, no. 11, pp. 849-856, 2009.

[6] M. Cilimkovic, "Neural Networks and Back Propagation Algorithm," Fett.Tu-Sofia.Bg, 2010.

[7] K. Husnul and S. Yuslena, "Prediksi kualitas hasil hutan lahan basah menggunakan Backpropagation," JTIULM, vol. 1, pp. 1-9, 2016.

[8] D. Gries and F. B. Schneider, Texts in Computer Science, vol. 42. Verlag London: Springer, 2010.

[9] B. C. Chang and Y. Hung, "A Neural Network-Based Prediction Model in Embedded Processes of Gold Wire Bonding Structure for Stacked Die Package," vol. 97, no. 1, 2009.

[10] R. F. F. S. C. R Development Core Team, R. E. Millsap, and C. W. J. Chase, "R: A Language and Environment for Statistical Computing," J. Bus. Forecast. Methods Syst., vol. 14, no. 3, pp. 461-473, 2014.

[11] T. Chai and R. R. Draxler, "Root mean square error (RMSE) or mean absolute error (MAE)? -Arguments against avoiding RMSE in the literature," Geosci. Model Dev., vol. 7, no. 3, pp. 1247-1250, 2014.

[12] S. Jachner, K. G. van den Boogaart, and T. Petzoldt, "Statistical Methods for the Qualitative Assessment of Dynamic Models with Time Delay (R Package qualV),” J. Stat. Softw., vol. 22, no. 8, pp. 1-30, 2007. 